\title{
Antisense-RNA-mediated plasmid copy number control in pCG1-family plasmids, pCGR2 and pCG1, in Corynebacterium glutamicum
}

\author{
Correspondence \\ Hideaki Yukawa \\ mmg-lab@rite.or.jp
}

Received 14 July 2010

Revised 25 August 2010

Accepted 26 August 2010

\author{
Naoko Okibe, Nobuaki Suzuki, Masayuki Inui and Hideaki Yukawa
}

Research Institute of Innovative Technology for the Earth, 9-2, Kizugawadai, Kizugawa, Kyoto 619-0292, Japan

\begin{abstract}
pCGR2 and pCG1 belong to different subfamilies of the pCG1 family of Corynebacterium glutamicum plasmids. Nonetheless, they harbour homologous putative antisense RNA genes, crrl and $\mathrm{cgrl}$, respectively. The genes in turn share identical positions complementary to the leader region of their respective $\operatorname{rep} A$ (encoding plasmid replication initiator) genes. Determination of their precise transcriptional start- and end-points revealed the presence of short antisense RNA molecules (72 bp, Crrl; and 73 bp, Cgrl). These short RNAs and their target mRNAs were predicted to form highly structured molecules comprising stem-loops with known U-turn motifs. Abolishing synthesis of $\mathrm{Crrl}$ and $\mathrm{Cgrl}$ by promoter mutagenesis resulted in about sevenfold increase in plasmid copy number on top of an 11-fold (Crrl) and 32-fold (Cgrl) increase in repA mRNA, suggesting that Crrl and Cgrl negatively control plasmid replication. This control is accentuated by par $B$, a gene that encodes a small centromere-binding plasmid-partitioning protein, and is located upstream of $\operatorname{rep} A$. Simultaneous deactivation of Crrl and parB led to a drastic 87-fold increase in copy number of a pCGR2-derived shuttle vector. Moreover, the fact that changes in the structure of the terminal loops of $\mathrm{Crrl}$ and $\mathrm{Cgrl}$ affected plasmid copy number buttressed the important role of the loop structure in formation of the initial interaction complexes between antisense RNAs and their target mRNAs. Similar antisense RNA control systems are likely to exist not only in the two C. glutamicum pCG1 subfamilies but also in related plasmids across Corynebacterium species.
\end{abstract}

\section{INTRODUCTION}

Plasmids are extrachromosomal, circular DNA molecules that replicate independently of chromosomal DNA. They typically possess specific DNA regions for their autonomous replication: an origin of replication (ori), a replication initiator protein (Rep; with a few exceptions where hostencoded proteins are used) and plasmid-harboured genes involved in replication control. As binding of Rep to ori is the first step of the replication process, availability of the rate-limiting Rep protein determines the replication frequency (and thus plasmid copy number) (del Solar et al., 1998). Plasmids have characteristic copy numbers within given cells. To maintain the copy number, the initiation step of plasmid replication is controlled either by negative regulation mechanisms involving antisense RNAs (with or without the joint action of a transcriptional repressor) or by iterons (del Solar et al., 1998). Antisense

Abbreviations: RT-qPCR, real-time quantitative RT-PCR; RACE, rapid amplification of CDNA ends; SD, Shine-Dalgarno.

The GenBank/EMBL/DDBJ accession number for the sequences of the E. coli-C. glutamicum shuttle vectors pCRB62 and pCRB12 are HM126493 and HM126494, respectively.
RNAs negatively regulating replication of bacterial plasmids are typically small (50-250 bp), short-lived, constitutively synthesized, cis-encoded, single-stranded RNA molecules that are complementary to the $5^{\prime}$ leader region of target mRNAs (Brantl, 2002; Khan, 1997; Rasooly \& Rasooly, 1997). The currently known antisense-RNA-mediated control mechanisms include transcription attenuation (Heidrich \& Brantl, 2007; Le Chatelier et al., 1996; Novick et al., 1989), translation inhibition (del Solar \& Espinosa, 2000), inhibition of primer maturation (Davison, 1984) and inhibition of pseudoknot formation (Athanasopoulos et al., 1999; Siemering et al., 1994). Antisense RNAs and their target mRNAs are generally highly structured, containing stem$\operatorname{loop}(\mathrm{s})$. Initial interaction of antisense RNAs and their target mRNAs often involves base pairing of two complementary loop pairs (kissing complex formation) (Brantl, 2007; Franch \& Gerdes, 2000). Recognition loops of antisense RNAs and their target mRNAs often possess a common structural U-turn motif [such as YUNR(UNR)- and GNRA-type consensus; Gutell et al., 2000] which mediates fast RNA pairing (Franch \& Gerdes, 2000; Franch et al., 1999).

A number of plasmids have been isolated from the highGC, Gram-positive industrial amino-acid-hyperproducing 
Corynebacterium glutamicum (Kinoshita et al., 1957). Most of these replicate via a rolling circle mechanism and belong either to the pCG1 or the pBL1 families. A few others replicate via the theta mechanism (Tauch, 2005). The $C$. glutamicum pCG1 family includes the small cryptic plasmids pCG1 (3069 bp: Ozaki et al., 1984), pGA1 (4826 bp: Sonnen et al., 1991), and pSR1 (3054 bp: Archer \& Sinskey, 1993) as well as larger plasmids (approx. 20-30 kb) such as pCG4, pAG1, pGA2, pTET3 and pCGR2 (Katsumata et al., 1984; Sonnen et al., 1991; Takeda et al., 1990; Tauch et al., 2002; Tsuchida et al., 2010). The C. glutamicum pCG1 family plasmids are further divided into two distinct subfamilies based on the presence or absence of the $\mathrm{Yux}_{3} \mathrm{k} / \mathrm{Yuxk}$ motif of replication initiator protein (Tauch et al., 2003b), which also effectively separates the subfamilies by plasmid size. The larger C. glutamicum pCG1 subfamily members possess a putative class $\mathrm{Ib}$ partitioning system (parAB operon) (Tauch et al., 2003b) which is essential for stable plasmid segregation to daughter cells. In the whole genus Corynebacterium, 14 additional pCG1 family plasmids are so far known [pNG2 (Tauch et al., 2003a); pBY503 (Kurusu et al., 1991); pLEW279a (Williams et al., 2006); pCE2 and pCE3 (Nishio et al., 2003); pYM2: (GenBank accession no. AB084384); pTP10 (Tauch et al., 2000); pKW4 (Tauch et al., 2005); pA501 (Brune et al., 2006); pK43, pK64, pCJ84 and pB85766 (Tauch et al., 2004); and pA505 (GenBank accession no. NC004773). pCG1 effectively represents the largest plasmid family of this species.

Replication control in C. glutamicum plasmids is poorly understood except for pGA1, whose replication is negatively controlled by a small antisense RNA (VenkovaCanova et al., 2003). Accessory elements of pGA1, encoded by the per and aes genes, positively influence stable maintenance of the plasmid but are not directly involved in controlling the frequency of replication initiation (Nešvera et al., 1997; Venkova et al., 2001). pCG1 harbours an ORF homologous to the pGA1 per gene (Tauch et al., 2003b) but pCG1 has not been analysed in any detail.

In this study, we set out to identify and characterize antisense RNAs negatively controlling replication of two $C$. glutamicum plasmids, pCG1 and pCGR2, each of which belongs to a different pCG1 subfamilys. Deletion of the partitioning gene revealed a high and robust control capacity of antisense RNA.

\section{METHODS}

Bacterial strains, plasmids and culture conditions. Bacterial strains and plasmids used are listed in Table 1. For genetic manipulation, Escherichia coli strains were grown at $37^{\circ} \mathrm{C}$ in $\mathrm{LB}$ medium (Sambrook et al., 1989). C. glutamicum was cultivated at $33{ }^{\circ} \mathrm{C}$ in $100 \mathrm{ml}$ rich medium (A medium supplemented with $4 \%$ glucose; Inui et al., 2007) except for the site-directed mutagenesis of CrrI and CgrI, where $10 \mathrm{ml}$ rich medium was used. When appropriate, E. coli and C. glutamicum media were supplemented with $50 \mu \mathrm{g}$ kanamycin $\mathrm{ml}^{-1}$.
Molecular techniques. Restriction endonucleases were purchased from Takara. DNA ligation and kination were performed using Mighty Mix and T4 polynucleotide kinase, respectively (Takara). PCR was performed using PrimeSTAR GXL DNA Polymerase or PrimeSTAR Max DNA Polymerase (Takara) and the resulting PCR fragments were purified with the QIAquick PCR purification kit (Qiagen). E. coli was transformed by the $\mathrm{CaCl}_{2}$ procedure (Sambrook et al., 1989) and $C$. glutamicum by electroporation (Vertès et al., 1993). DNA sequences were determined using the BigDye Terminator v3.1 Cycle Sequencing kit with an ABI 3130xl/3730xl genetic analyser (Applied Biosystems). The sequence data were analysed using Genetyx software.

Construction of pCG1- and pCGR2-derived shuttle vectors. $E$. coli-C. glutamicum shuttle vectors, pCRB62 and pCRB12, derived from pCGR2 and pCG1, respectively, were constructed and deposited in GenBank with accession numbers HM126493 and HM126494, respectively (Table 1 ). In order to obtain a variety of pCGR2 and pCG1 derivatives (Table 1), inverse PCR was performed (i) to introduce nucleotide mutations in the -10 regions of the cgrI promoter (PcgrI) and crrI promoter (PcrrI), (ii) to delete target DNA regions ( $p a r A, \operatorname{parB}$ or both), and (iii) to frameshift the parB gene (by exchanging $7 \mathrm{nt}$ after ATG with a SpeI restriction site) using primers listed in Table 2. To construct pCRB62 ${ }^{\mathrm{mt}}$ and $\mathrm{pCRB} 12^{\mathrm{mt}}$, pCRB62 and pCRB12, respectively, were used as template DNA for inverse PCR. Construction of pCRB62 derivatives with wild-type P crrI used pCRB62 as template DNA, whereas derivatives with mutated PcrrI used pCRB6 $2^{\mathrm{mt}}$. Inverse PCR fragments were then self-ligated and used to transform E. coli cells. C. glutamicum was transformed with the resulting constructs. C. glutamicum harbouring each plasmid was grown in $100 \mathrm{ml}$ rich medium and $1 \mathrm{ml}$ late-exponential phase $\left(\mathrm{OD}_{610}\right.$ 6.0) culture was withdrawn for extraction of total DNA and RNA.

Site-directed mutagenesis of Crrl and Cgrl. Inverse PCR was performed to obtain CrrI and CgrI mutants using pCRB62(B $\left.{ }^{-}\right)$and pCRB12 as template DNA, respectively. The CrrI mutants (CrrI-mt1 to CrrI-mt6) resulted from mutated forms of plasmid pCRB62(B $\left.{ }^{-}\right)$, p62 $\left(B^{-}\right)-m t 1$ to p62 $\left(B^{-}\right)-m t 6$, respectively (Tables 1 and 2). CgrI mutants, CgrI-mt1 to CgrI-mt5, resulted from mutated forms of plasmid pCRB12, p12-mt1 to p12-mt5, respectively (Tables 1 and 2). Inverse PCR fragments were then self-ligated and used to transform $E$. coli cells. C. glutamicum was transformed with the resulting constructs.

Nucleic acid extraction. Plasmid DNA was extracted by the alkaline lysis method (Sambrook et al., 1989), or using a Miniprep kit (Qiagen) according to the manufacturer's instructions. The DNA extraction procedures were modified by pre-treating C. glutamicum with $4 \mathrm{mg}$ lysozyme $\mathrm{ml}^{-1}$ (Sigma-Aldrich) at $37^{\circ} \mathrm{C}$ for $1 \mathrm{~h}$.

For plasmid copy number analysis, total DNA was extracted from $1 \mathrm{ml}$ late-exponential-phase $\left(\mathrm{OD}_{610} 6.0\right)$ C. glutamicum cultures. The detailed procedure is described elsewhere (Tsuchida et al., 2009).

For total RNA extraction, samples withdrawn from late-exponentialphase C. glutamicum cultures $\left(\mathrm{OD}_{610} 6.0\right)$ were mixed with 1 vol. RNAprotect Bacteria Reagent (Qiagen), incubated at room temperature for $10 \mathrm{~min}$, and centrifuged at $6000 \mathrm{~g}$ for $10 \mathrm{~min}$ at room temperature. The resultant pellet was resuspended in QIAzol lysis reagent (miRNeasy kit, Qiagen) and subsequently disrupted using $0.1 \mathrm{~mm}$ zirconia/silica beads (BioSpec Products) by eight $45 \mathrm{~s}$ cycles at a speed of $6.5 \mathrm{~m} \mathrm{~s}^{-1}$ in a FastPrep FP100A Instrument (Q-BIOgene). After removal of the cell debris, RNA was extracted using the miRNeasy kit (Qiagen) according to the manufacturer's instructions.

Rapid amplification of cDNA ends (RACE). The $5^{\prime}$ - and $3^{\prime}$-ends of the antisense RNA genes ( $c r r I$ and $c g r I)$ and the $5^{\prime}$-ends of repA genes were localized using a SMART RACE cDNA amplification kit (Clontech). For determination of the $5^{\prime}$ - and $3^{\prime}$-ends of crrI and cgrI, total RNA extracted from C. glutamicum harbouring pCRB12 or 
Table 1. Bacterial strains and plasmids used in this study

\begin{tabular}{|c|c|c|}
\hline Strain/plasmid & Relevant genotype/property & Source/reference \\
\hline \multicolumn{3}{|l|}{ Strains } \\
\hline \multicolumn{3}{|l|}{ E. coli } \\
\hline SCS110 & $\begin{array}{l}\text { dam dcm endA1 supE44 hsdR17 thi leu rpsL1 lacY galK galT ara tonA thr } \Delta \text { (lac-proAB)/ } \\
\mathrm{F}^{\prime}\left[\text { traD36 proAB }{ }^{+} \text {lacl }^{\mathrm{q}} \text { lacZ } \Delta M 15\right]\end{array}$ & TOYOBO \\
\hline \multicolumn{3}{|l|}{ Plasmids } \\
\hline pCGR2 & $24 \mathrm{~kb}$ plasmid from C. glutamicum & Tsuchida et al. (2010) \\
\hline \multicolumn{3}{|l|}{ pCGR2 derivatives } \\
\hline pCRB62 & $\mathrm{Km}^{\mathrm{r}}$; E. coli-C. glutamicum shuttle vector based on pCGR2; 5914 bp & GenBank HM126493 \\
\hline pCRB62 $\left(\mathrm{A}^{-}\right)$ & $\mathrm{Km}^{\mathrm{r}}$; pCRB62; parA ORF removed & This study \\
\hline pCRB62 $\left(\mathrm{B}^{-}\right)$ & $\mathrm{Km}^{\mathrm{r}}$; pCRB62; parB ORF removed & This study \\
\hline pCRB62 $2^{\mathrm{mt}}\left(\mathrm{B}^{-}\right)$ & $\mathrm{Km}^{\mathrm{r}}$; pCRB62; $\mathrm{crrI}$ promoter mutated and parB ORF removed & This study \\
\hline $\mathrm{pCRB} 62^{\mathrm{mt}}\left(\mathrm{AB}^{-}\right)$ & $\mathrm{Km}^{\mathrm{r}}$; pCRB62; $\mathrm{crrI}$ promoter mutated and parA and parB ORFs removed & This study \\
\hline pCRB62 $2^{\mathrm{mt}}(\mathrm{Bfs})$ & $\mathrm{Km}^{\mathrm{r}} ;$ pCRB62; crrI promoter mutated and parB ORF frame shifted & This study \\
\hline \multicolumn{3}{|l|}{ pCG1 derivatives } \\
\hline pCG1 & 3069 bp plasmid from C. glutamicum & Ozaki et al. (1984) \\
\hline pCRB12 & $\mathrm{Km}^{\mathrm{r}} ;$ E. coli-C. glutamicum shuttle vector based on pCG1; 4569 bp & GenBank HM126494 \\
\hline $\mathrm{pCRB} 12^{\mathrm{mt}}$ & $\mathrm{Km}^{\mathrm{r}} ;$ pCRB12; $\operatorname{cgrI}$ promoter mutated & This study \\
\hline \multicolumn{3}{|c|}{ pCRB62 $\left(B^{-}\right)$derivatives } \\
\hline $\mathrm{p} 62\left(\mathrm{~B}^{-}\right)-\mathrm{mt} 1$ & $\mathrm{Km}^{\mathrm{r}}$; a derivative of pCRB62 $\left(\mathrm{B}^{-}\right)$with a mutant CrrI (CrrI-mt1) & This study \\
\hline $\mathrm{p} 62\left(\mathrm{~B}^{-}\right)-\mathrm{mt} 2$ & $\mathrm{Km}^{\mathrm{r}}$; a derivative of pCRB62 $\left(\mathrm{B}^{-}\right)$with a mutant CrrI (CrrI-mt2) & This study \\
\hline $\mathrm{p} 62\left(\mathrm{~B}^{-}\right)-\mathrm{mt} 3$ & $\mathrm{Km}^{\mathrm{r}}$; a derivative of pCRB62 $\left(\mathrm{B}^{-}\right)$with a mutant CrrI (CrrI-mt3) & This study \\
\hline \multicolumn{3}{|l|}{$p C R B 12$ derivatives } \\
\hline p12-mt4 & $\mathrm{Km}^{\mathrm{r}}$; a derivative of pCRB12 with a mutant CgrI (CgrI-mt4) & This study \\
\hline p12-mt5 & $\mathrm{Km}^{\mathrm{r}}$; a derivative of pCRB12 with a mutant CgrI (CgrI-mt5) & This study \\
\hline
\end{tabular}

pCRB62, respectively, was polyA-tailed prior to the RACE reactions, using the Poly(A)-Tailing kit (Applied Biosystems). The first strand synthesis was performed using the primers from the kit, followed by PCR (and further nested-PCR for 5'-RACE) using the gene-specific primers listed in Table 2. The gene-specific primers used for firststrand synthesis and PCRs to localize the $5^{\prime}$-ends of repA genes are listed in Table 2. The resulting PCR products were TA-cloned using the pGEM-T Easy Vector System (Promega) and sequenced.

Detection of Crrl and Cgrl by RNase protection assay. Construction of antisense RNA probes and the downstream RNA hybridization/detection were performed using the mirVana miRNA Probe Construction kit (Ambion) and mirVana miRNA Detection kit (Ambion), respectively, according to the manufacturer's instructions. The DNA oligonucleotide template for transcription of antisense RNA probes was designed to cover the full $\mathrm{crrI}$ gene (72 bp) or cgrI gene (73 bp) plus the $8 \mathrm{nt}$ sequence $5^{\prime}$-CCTGTCTC- $3^{\prime}$ added to the $3^{\prime}$-end. The DNA oligonucleotide template was then annealed to the supplied T7 promoter primer and filled in with Klenow DNA polymerase. Transcription reactions were performed using Cy-3- labelled UTP. Total RNA $(0.5 \mu \mathrm{g})$ extracted from late-exponentialphase cultures of C. glutamicum harbouring pCRB62, pCRB62 ${ }^{\mathrm{mt}}$, pCRB12 and pCRB12 ${ }^{\text {mt }}$ was hybridized with the Cy-3-labelled antisense RNA probes at $42{ }^{\circ} \mathrm{C}$ for $3.5 \mathrm{~h}$, followed by RNase digestion of unhybridized RNA species and excess RNA probes. Cy-3-labelled protected RNA probe fragments were then analysed on $10 \%$ TBEUrea gel (Novex) and visualized using a laser gel scanner (Typhoon Trio, GE Healthcare).

Real-time quantitative PCR (RT-qPCR). mRNA was quantified using the ABI 7500 Fast Real-Time PCR System (Applied Biosystems). Each RT-PCR $(20 \mu \mathrm{l})$ contained $10 \mu \mathrm{l}$ Power SYBR Green Master Mix (Applied Biosystems), $150 \mathrm{nM}$ forward/reverse primer, $5 \mathrm{U}$ MuLV reverse transcriptase (Applied Biosystems), $8 \mathrm{U}$ RNase inhibitor and 100 ng total RNA (1 ng total RNA for the reference 16S rRNA gene). Transcripts of the 16S rRNA and repA genes were quantified using primers listed in Table 2. The target gene transcripts were normalized to the reference gene transcripts (16S rRNA) from the same RNA samples. Reactions were performed as follows: $50{ }^{\circ} \mathrm{C}$ for $30 \mathrm{~min}$, $95{ }^{\circ} \mathrm{C}$ for $10 \mathrm{~min}$, followed by 40 cycles of $95{ }^{\circ} \mathrm{C}$ for $15 \mathrm{~s}$ and $60{ }^{\circ} \mathrm{C}$ 
Table 2. Primers used in this study

\begin{tabular}{|c|c|c|}
\hline Purpose & Primer name & Sequence $\left(5^{\prime}-3^{\prime}\right)^{\star}$ \\
\hline \multicolumn{3}{|c|}{$\begin{array}{l}\text { Inverse PCR to construct the following pCG1 and pCGR2 } \\
\text { derivatives }\end{array}$} \\
\hline \multirow[t]{2}{*}{$\mathrm{pCRB} 12^{\mathrm{mt}}$} & $12 \mathrm{mt} \_\mathrm{f}$ & AAAAATGACCCTGGCGGATT \\
\hline & $12 \mathrm{mt} \_\mathrm{r}$ & AATCCGCCAGGGTCATTTTT \\
\hline \multirow[t]{2}{*}{ pCRB $62^{\mathrm{mt}}$} & $62 \mathrm{mt} \_\mathrm{f}$ & CAATGAGTTTGCCTTCAAAAGGACGATCAAGC \\
\hline & 62mt_r & ACGTGCTTTCCCCCGGGTGTCCT \\
\hline \multirow[t]{2}{*}{$\mathrm{pCRB} 62\left(\mathrm{~A}^{-}\right)$and $\mathrm{pCRB} 62^{\mathrm{mt}}\left(\mathrm{A}^{-}\right)$} & 62rmvA_f & ATGGCTGATTTATCCAAGAAGCTGG \\
\hline & 62rmvA_r & AAGAACACTATGACATACAAACGTCAC \\
\hline \multirow[t]{2}{*}{$\mathrm{pCRB} 62\left(\mathrm{~B}^{-}\right)$and $\mathrm{pCRB} 62^{\mathrm{mt}}\left(\mathrm{B}^{-}\right)$} & 62rmvB_f & GTATGTTTGTATGTCATGGCATACGAC \\
\hline & 62rmvB_r & CCATTAATGTTCTCCCAACAGGTTTGA \\
\hline \multirow[t]{2}{*}{$\mathrm{pCRB} 62\left(\mathrm{AB}^{-}\right)$and $\mathrm{pCRB} 62^{\mathrm{mt}}\left(\mathrm{AB}^{-}\right)$} & 62rmvAB_f & GTATGTTTGTATGTCATGGCATACGAC \\
\hline & 62rmvAB_r & AAGAACACTATGACATACAAACGTCAC \\
\hline \multirow[t]{2}{*}{ pCRB62(Bfs) and pCRB62 ${ }^{\mathrm{mt}}(\mathrm{Bfs})$} & SpeI_fsB_f & TCTCACTAGTTATCCAAGAAGCTGGCGAAAA \\
\hline & SpeI_fsB_r & TCTCACTAGTCATTAATGTTCTCCCAACAGGTT \\
\hline \multicolumn{3}{|c|}{ RACE for the pCG1 antisense RNA gene (cgrI) } \\
\hline $5^{\prime}$-RACE PCR & cgr_5RACE & GTTGAACGCCCCGTGAGCGGTAACTCAC \\
\hline 5'-RACE nested PCR & cgr_5RACE-N & CTCACAGGGCGTCGGCTAACCCCCAGTC \\
\hline 3'-RACE PCR & cgr_3RACE & CTCCCAGGTTTGGACTGGGGGTTAGCCG \\
\hline \multicolumn{3}{|c|}{ RACE for the pCGR2 antisense RNA gene ( $c r r I)$} \\
\hline 5'-RACE PCR & crr_5RACE & TGCATGAAGTCCGCCAGGCTTGCACCCC \\
\hline 5'-RACE nested PCR & crr_5RACE-N & ACCCCTGACGGACTTCGCTATCACCCGG \\
\hline 3'-RACE PCR & crr_3RACE & CCCGGGTGTCCTCCGGGTGATAGCGA \\
\hline \multicolumn{3}{|l|}{ RACE for the pCG1 repA gene } \\
\hline First strand synthesis & 12rep_1st & TGGATTCACGCCGATCCAAGCT \\
\hline 5'-RACE PCR & 12rep_5RACE & ACGGCTGCGTGCTGCGCGTGCGTCAGA \\
\hline \multicolumn{3}{|l|}{ RACE for the pCGR2 repA gene } \\
\hline First strand synthesis & 62rep_1st & CGTTTGTGCTGGCAATACCAACGATA \\
\hline $5^{\prime}$-RACE PCR & 62rep_5RACE & AGCACGGCTCGTCGCGGCAAGCAGACTC \\
\hline 5'-RACE nested PCR & 62rep_5RACE-N & GGGCGAAGAGTACCGTCCTCGTGGCGGT \\
\hline \multicolumn{3}{|c|}{ qRT-PCR for quantification of the following genes } \\
\hline \multirow[t]{2}{*}{ 16S rRNA gene } & 16S_qRT_f & CCGGTACGGCTACCTTGTTA \\
\hline & 16S_qRT_r & CCGTCACGTCATGAAAGTTG \\
\hline \multirow[t]{2}{*}{ repA (pCRB12) } & 12rep_qRT_f & TCAACGACAAGCTAGGAAAGC \\
\hline & 12rep_qRT_r & AGCCAGTCTCTCCCTCAACA \\
\hline \multirow[t]{2}{*}{ repA (pCRB62) } & 62rep_qRT_f & CTTTGGGTGAGCTGTTGGAT \\
\hline & 62rep_qRT_r & TACCAACGATAGGCGGTAGG \\
\hline \multicolumn{3}{|c|}{ Inverse PCR mutagenesis of the CrrI region of pCRB62(B-) } \\
\hline \multirow[t]{2}{*}{$\mathrm{p} 62\left(\mathrm{~B}^{-}\right)-\mathrm{mt} 1$} & $\mathrm{mt} 1-\mathrm{f}$ & TTGaACCCCTGACGGACTTCGCTA \\
\hline & $\mathrm{mt} 1236-\mathrm{r}$ & GCCTGGCGGACTTCATGCATTTATAAGG \\
\hline $\mathrm{p} 62\left(\mathrm{~B}^{-}\right)-\mathrm{mt} 2 \dagger$ & $\mathrm{mt} 2-\mathrm{f}$ & TTcCACCCCTGACGGACTTCGCTA \\
\hline \multirow{3}{*}{$\begin{array}{l}\mathrm{p} 62\left(\mathrm{~B}^{-}\right)-\mathrm{mt} 3 \dagger \\
\mathrm{p} 62\left(\mathrm{~B}^{-}\right)-\mathrm{mt} 4\end{array}$} & $m t 3-f$ & TTcaACCCCTGACGGACTTCGCTA \\
\hline & $\mathrm{mt} 45-\mathrm{f}$ & GAGGACACCCGGGGGAAAGCA \\
\hline & $\mathrm{mt} 4-\mathrm{r}$ & CGGGgGATAGCGAAGTCCGTCA \\
\hline $\mathrm{p} 62\left(\mathrm{~B}^{-}\right)-\mathrm{mt} 5 \ddagger$ & $\mathrm{mt5}-\mathrm{r}$ & CGGGgGAaAGCGAAGTCCGTCA \\
\hline $\mathrm{p} 62\left(\mathrm{~B}^{-}\right)-\mathrm{mt} 6 \dagger$ & $m t 6-f$ & TTGCACgCCTGACGGACTTCGCTA \\
\hline \multicolumn{3}{|c|}{ Inverse PCR mutagenesis of the CgrI region of pCRB12 } \\
\hline p12-mt1 & CG-mt1-f & TCCAcACCTGGGAGAAAGCGCTCA \\
\hline & CG-mt1-r & CTGGGGGTTAGCCGACGCCCTGT \\
\hline p12-mt2 & CG-mt23-f & CTGGGAGAAAGCGCTCAAAAATGACTCTAGC \\
\hline & CG-mt2-r & GTTTcGACTGGGGGTTAGCCGACG \\
\hline p12-mt3\$ & CG-mt3-r & GTgaGGACTGGGGGTTAGCCGAC \\
\hline p12-mt4 & CG-mt4-f & ttCCCCCAGTCCAAACCTGGGAGA \\
\hline & CG-mt4-r & AGCCGACGCCCTGTGAGTTACC \\
\hline p12-mt5 & CG-mt5-f & CCCCAGgCCAAACCTGGGAGAAAG \\
\hline & CG-mt5-r & GTTAGCCGACGCCCTGTGAGTTAC \\
\hline
\end{tabular}


Table 2. cont.

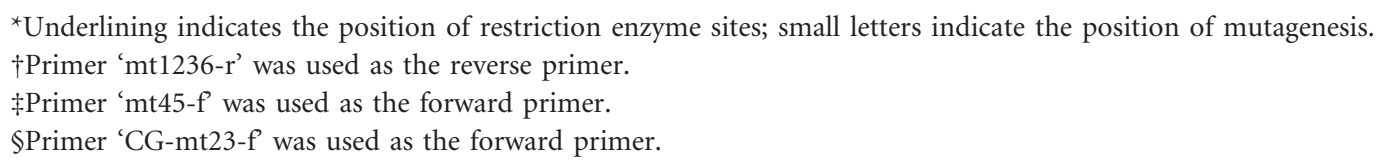

for $30 \mathrm{~s}$. The results, referred to as $C_{\mathrm{T}}$ (cycle threshold) values, were means of triplicate experiments.

Quantification of the plasmid copy number by absolute realtime quantitative PCR (absolute RT-qPCR). Plasmid copy number was calculated as the ratio of quantified aph (a single-copy gene on the plasmids) to dnaA (a single-copy gene on C. glutamicum $\mathrm{R}$ chromosome). Details of primer design to target four $d n a A$ and $a p h$ sites, production of a standard curve and RT-qPCR analysis were as described elsewhere (Tsuchida et al., 2009), except that serial dilution series of plasmids containing dnaA or aph sequence were made ranging from $1 \times 10^{4}$ to $1 \times 10^{8}$ or $1 \times 10^{5}$ to $1 \times 10^{9}$ copies $\mu \mathrm{l}^{-1}$, respectively, to produce standard curves.

RNA secondary structure prediction. The secondary structures of the antisense RNA molecules and the target repA mRNAs were predicted by the RNAfold program (Hofacker et al., 1994; http://rna. tbi.univie.ac.at/cgi-bin/RNAfold.cgi), using algorithms for calculating minimum free energy (MFE) and partition function. Isolated base pairs were avoided in the structure prediction.

\section{RESULTS}

\section{pCG1 family plasmids PCGR2 and pCG1 harbour small antisense RNA genes in the repA leader region}

Regions immediately upstream of the replication initiation protein genes on plasmids pCGR2 and pCG1 were investigated for the presence of antisense RNA genes. Due to the small size of antisense RNA genes, using genespecific primers for first-strand synthesis for $5^{\prime}$-RACE was not feasible, meaning that total RNA had to be polyA-tailed first to extend the length of the target mRNA. The same procedure was necessary to determine the $3^{\prime}$-end. The result was that the $<200 \mathrm{bp}$ of $5^{\prime} / 3^{\prime}$-RACE products could be amplified and cloned. Thereafter nucleotide sequencing identified the transcription start- and end-points of the pCGR2 antisense RNA gene at 5 and 76 bp upstream of the repA initiation codon, implying the presence of a $72 \mathrm{bp}$ gene (Fig. 1a). Likewise, a 73 bp gene was shown to be contained on the pCG1 plasmid with transcriptional startand end-points at 5 and $77 \mathrm{bp}$ upstream of the repA initiation codon (Fig. 1b). We named the gene contained on pCGR2 crrI and that on pCG1 cgrI. The transcriptional start point of the pCGR2 repA gene was determined to be 85 bp upstream of the initiation of the translation codon. That of the pCG1 repA gene was 89 bp upstream of the initiation of translation codon. Putative promoter sequences of pCGR2 repA ( $-35,5^{\prime}$-GGCACA-3'; -10 , $5^{\prime}$-TACTCT-3', Fig. 1a) and pCG1 repA $\left(-35,5^{\prime}\right.$-CGCfACA-3'; $-10,5^{\prime}$-TAAGCT-3', Fig. 1b) were determined and shown to share sequence similarity with the $C$. glutamicum promoter consensus (Pátek et al., 2003). The crrI and cgrI genes were therefore contained within the repA leader regions of their respective plasmids, but in opposite orientation to repA. Putative promoter regions of crrI (-35, 5'-GTGCTT-3'; -10, 5'-TAGGCT-3', Fig. 1a) and $\operatorname{crgI}\left(-35,5^{\prime}\right.$-GTGTCA-3'; -10, 5'-TAGAGT-3', Fig. 1b) with sequence similarity to the C. glutamicum promoter consensus (Pátek et al., 2003) were observed.

In order to confirm promoter activity, the -10 sequence of crrI on pCRB62 (pCGR2-derived shuttle vector; Table 1) was altered to $5^{\prime}$-CAAACT- $3^{\prime}$ to construct pCRB62 ${ }^{\mathrm{mt}}$ (Fig. 1a). This alteration did not change the amino acid sequence (Ser, Leu) of the complementary repA gene. Likewise, the $\operatorname{crgI}-10$ sequence on pCRB12 (pCG1derived shuttle vector; Table 1) was altered to 5'CAGGGT-3' to obtain pCRB12 ${ }^{\mathrm{mt}}$ (Fig. 1b) so that the amino acid residues (Thr, Leu) encoded by the corresponding region of complementary repA gene remained unchanged. Expression of antisense RNAs of pCRB62, $\mathrm{pCRB}^{\mathrm{mt}}{ }^{2}, \mathrm{pCRB} 12$ and $\mathrm{pCRB} 12^{\mathrm{mt}}$ were visualized by RNase protection assay (Fig. 2). CrrI and CgrI were detected from wild-type plasmids pCRB62 (Fig. 2a) and pCRB12 (Fig. 2b), respectively, but introducing mutation in the -10 region hindered expression of the antisense RNAs. The results clearly suggest that the putative promoter regions indeed function to express antisense RNAs.

\section{Predicted secondary structures of Crrl and Cgrl and their target mRNA leader regions}

The predicted secondary structures of the antisense RNA molecules and the target repA mRNAs are shown in Fig. 3. CrrI was predicted to form a secondary structure with two stem-loops with a minimum free energy of $-41.8 \mathrm{kcal}$ $\mathrm{mol}^{-1}\left(-175 \mathrm{~kJ} \mathrm{~mol}^{-1}\right)$ (Fig. 3a). The first stem-loop consists of a GC-rich 13 bp StemI with a 5 bp terminal LoopI. The second consists of a GC-rich 13 bp StemII and an 8 bp LoopII. A sequence (5'-CUUUC- $\left.3^{\prime}\right)$ complementary to the putative repA Shine-Dalgarno (SD) sequence was located at the $5^{\prime}$-end of CrrI. LoopI (5'-UGUCC-3') and LoopII (5'-GGUGCAAG-3') of CrrI are complementary to a part of LoopI' (5'-GGACA-3') and LoopII' (5'CUUGCACC- $\left.3^{\prime}\right)$, respectively, of sense RNA. A GNRA Uturn motif (5'-GCAA-3') was present in LoopII of CrrI. LoopII' of sense RNA possessed a YUNR motif whose complementary sequence on CrrI LoopII (5'-CAAG-3') partially overlapped the GNRA motif (Fig. 3a). 
(a)

4426

CACGCAGACA GTGCGTCTGTATTGTTGCAATATCACGAAACTGCGATTTGACATAGCCCCGTCCAATTTTTGAAAAGCACAGCGCCCGTG

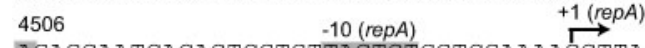

AGAGCAATCACACTCGTGTTACTCTGGTCGAAAACCTTATAAATGCATGAAGTCCGCCAGGCTTGCACCCCTGACGGACT TCTCGTTAGTGTGAGCACAATGAGACCAGCTTTTGGAATATTTACGTACTTCAGGCGGTCCGAACGTGGGGACTGCCTGA $4586 \quad$ SD (repA) +86 repA TCGCTATCACCCGGAGGACACCCGGGGGAAAGCACGTCA ATGAGCCTACCTTCAAAAGGACGATCAAGCACACCCACGGG AGCGATAGTGGGCCTCCTGTGGGCCCCCTTTCGTGCAGTTACTCGGATGGAAGTTTTCCTGCTAGTTCGTGTGGGTGCCC

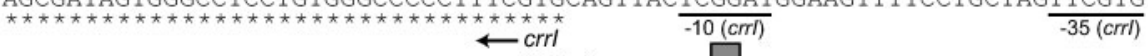

(72bp)

(b)

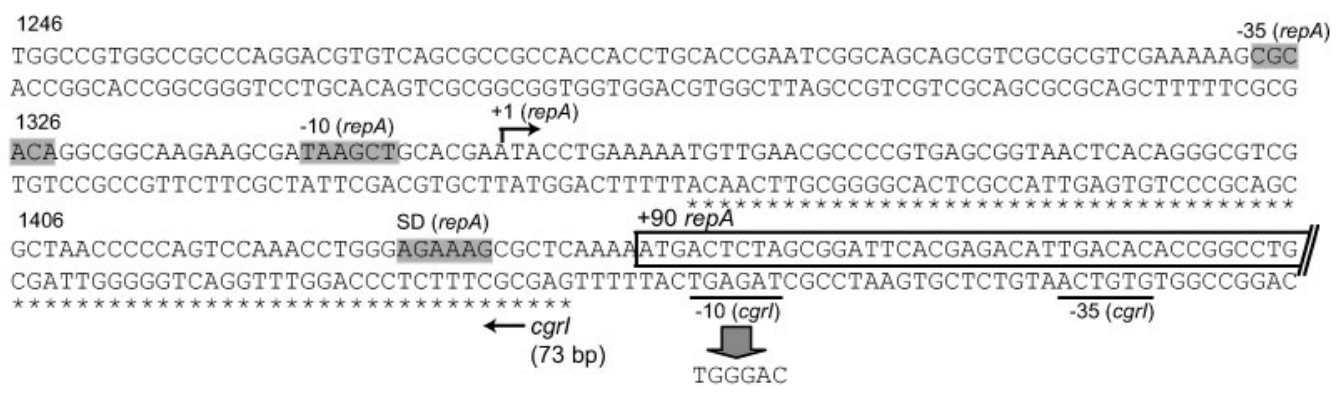

Fig. 1. Organization of $r e p A$ and the antisense RNA genes of pCGR2 (crrl) (a) and pCG1 (cgrl) (b). The repA ORFs are boxed. Asterisks indicate the antisense RNA coding regions. Transcriptional start points of repA are indicated by bent arrows marked +1 . The putative $-35,-10$ and Shine-Dalgano (SD) regions of repA are shaded. The putative -35 and -10 regions of antisense RNA genes are underlined. Numbers indicate the position on the native plasmid DNA. Mutations generated in this study to inactivate the antisense RNA promoters are indicated underneath the -10 sequences.

(a)

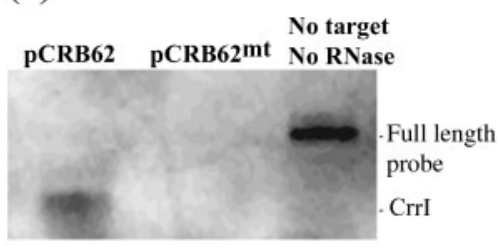

(b)

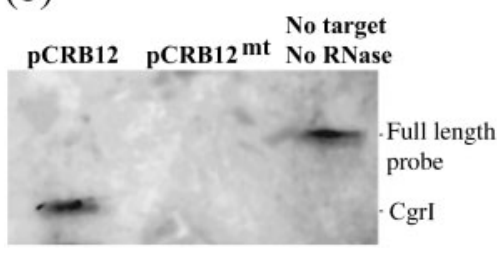

Fig. 2. Detection of Crrl (a) and Cgrl (b) by RNase protection assay. (a) Crrl (72 bp) expressed from pCRB62 is shown in the left lane, and that from pCRB62 ${ }^{\text {mt }}$ (Pcrrl mutated) in the middle lane. Full-length probe $(80 \mathrm{bp})$ is visible in the no target/no RNase control in the right lane. (b) Cgrl (73 bp) expressed from pCRB12 is shown in the left lane, and that from pCRB12 $2^{\mathrm{mt}}$ (Pcgrl mutated) in the middle lane. Full-length probe ( $81 \mathrm{bp})$ is visible in the no target/no RNase control in the right lane.
CgrI was also predicted to form a secondary structure with two stem-loops (Fig. 3b), with a minimum free energy of $-43.8 \mathrm{kcal} \mathrm{mol}^{-1}\left(-183 \mathrm{~kJ} \mathrm{~mol}^{-1}\right)$. The first loop consists of a GC-rich $12 \mathrm{bp}$ StemI with a $7 \mathrm{bp}$ terminal LoopI containing the YUNR U-turn motif ( $5^{\prime}$-UUGG-3'). The second loop comprises a GC-rich 11 bp StemII with a 4 bp terminal LoopII. Similar to CrrI, the $5^{\prime}$-end of CgrI contained a sequence $\left(5^{\prime}\right.$-CUUUCU- $\left.3^{\prime}\right)$ complementary to the putative SD sequence of pCG1 repA. LoopI (5'GUUUGGA-3') and LoopII (5'-UACC-3') of CgrI were complementary to LoopI' (5'-UCCAAAC- $\left.3^{\prime}\right)$ and a part of LoopII' (5'-GGUA-3'), respectively, of the pCG1 repA mRNA leader region.

\section{Crrl and Cgrl negatively control plasmid copy number}

The effect of the antisense RNAs on repA mRNA transcription level and plasmid copy number was investigated by RT-qPCR and absolute RT-qPCR, respectively. Under the control of CrrI, the mean copy number of pCGR2-derived pCRB62 was 2.5 copies per chromosome. By inactivating PcrrI (pCRB62 ${ }^{\mathrm{mt}}$ ), the copy number increased 6.6-fold, reaching a maximum of 16.6 copies per chromosome. The repA mRNA level of pCRB $62^{\mathrm{mt}}$ increased even more dramatically than plasmid copy number: it was 31.7-fold higher than that of pCRB62 
(a)
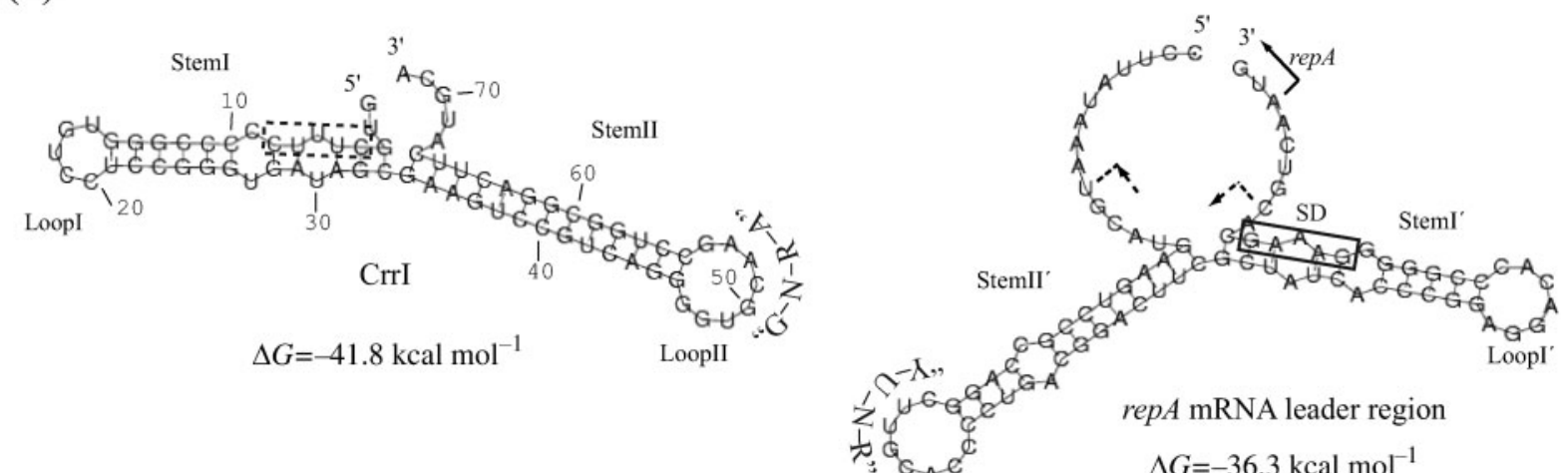

(b)
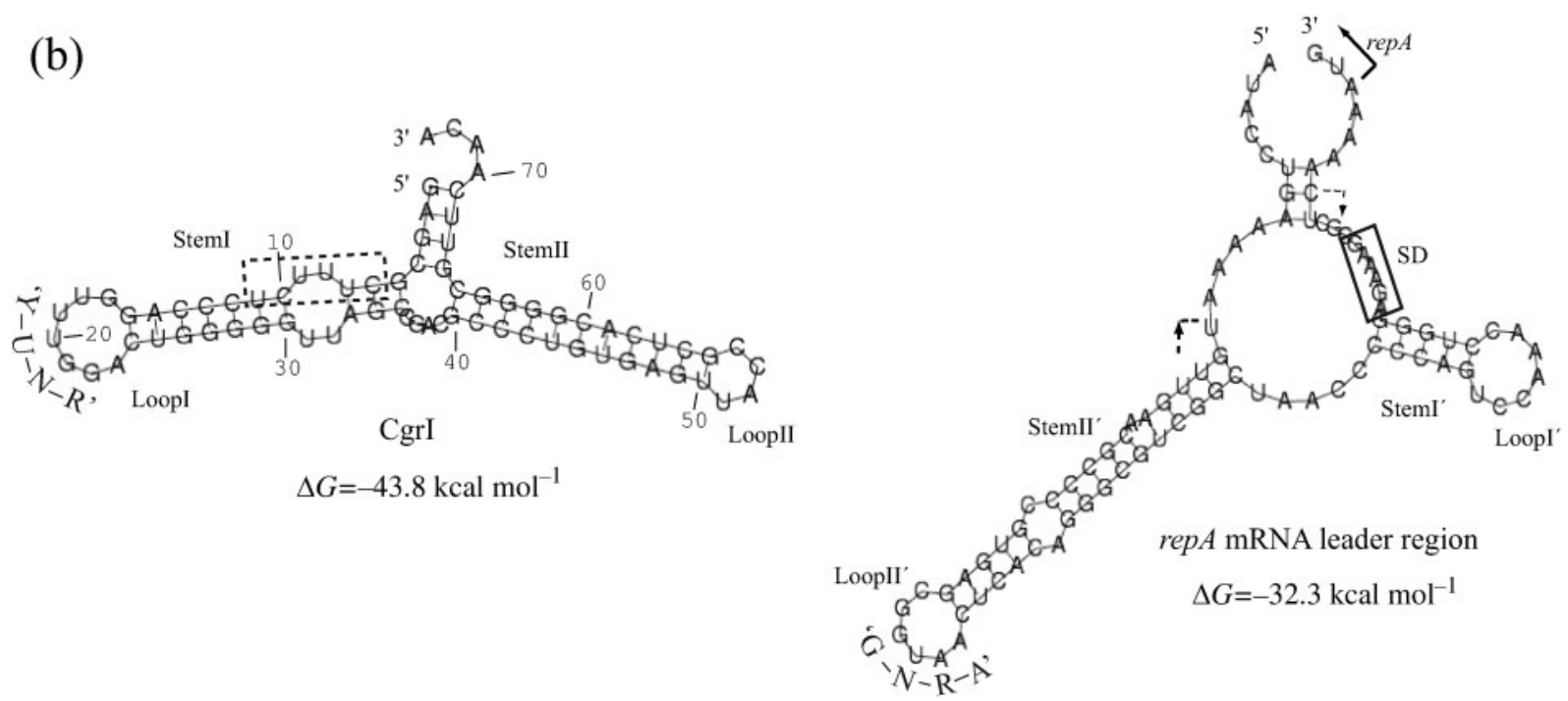

Fig. 3. Predicted secondary structures of antisense RNA and the target repA mRNA leader regions of pCGR2 (a) and pCG1 (b), analysed by RNAfold. Putative SD sequences of repA are boxed with unbroken lines and marked 'SD'. The sequences complementary to the $\operatorname{rep} A \mathrm{SD}$ sequences are boxed with broken lines. Unbroken arrows indicate the start site of the repA genes. Broken arrows indicate regions complementary to the antisense RNA genes. Nucleotide positions are numbered on the RNA molecules. A minimum free energy $(\Delta G)$ is indicated for each secondary structure $(1 \mathrm{kcal}=4.184 \mathrm{~kJ})$. The stem and terminal loop regions of the antisense RNAs Crrl and Cgrl are named Steml, Stemll, Loopl and Loopll. Those of the sense RNAs are named Steml', Stemll', Loopl' and Loopll'. The U-turn consensus (GNRA and YUNR) motifs are indicated for the antisense and sense RNA loops.

(Fig. 4). Similar results were obtained with pCG1-derived pCRB12. Inactivation of P cgrI caused a 6.7-fold increase in mean plasmid copy number (from 4.6 to 30.8 copies per chromosome), and an approximately 11 -fold increase in repA mRNA level. The results clearly show that CrrI and CgrI negatively regulate the plasmid copy number.

\section{The partitioning gene parB accentuates the effect of antisense RNA on pCGR2 copy number}

Negative regulation of pCGR2 replication by CrrI was clearly shown by the results described above. However, the 6.6-fold increase of pCGR2 copy number caused by inactivation of PcrrI was far less than the 60 -fold increase observed by Tsuchida et al. (2010) using a different pCGR2-derived plasmid, pCRD324. The only structural difference between these two pCGR2 derivatives is the presence in PCRB62 of a putative partitioning operon upstream of repA that pCRD324 lacks. Therefore, in order to investigate if the partitioning genes have any effect on the plasmid copy number, we constructed six other pCGR2 derivatives by deleting one or both of the two partitioning genes from pCRB62 and pCRB62 ${ }^{\mathrm{mt}}$ (Fig. 4). pCRB62 $\left(\mathrm{A}^{-}\right.$) and pCRB $62^{\mathrm{mt}}\left(\mathrm{A}^{-}\right)$showed similar mRNA levels and copy numbers to pCRB62 and pCRB62 ${ }^{\mathrm{mt}}$, respectively, indicating that deleting the parA ORF did not affect the frequency of the plasmid replication. In contrast, as observed for $\mathrm{pCRB} 62^{\mathrm{mt}}\left(\mathrm{B}^{-}\right)$, deleting the parB ORF in 


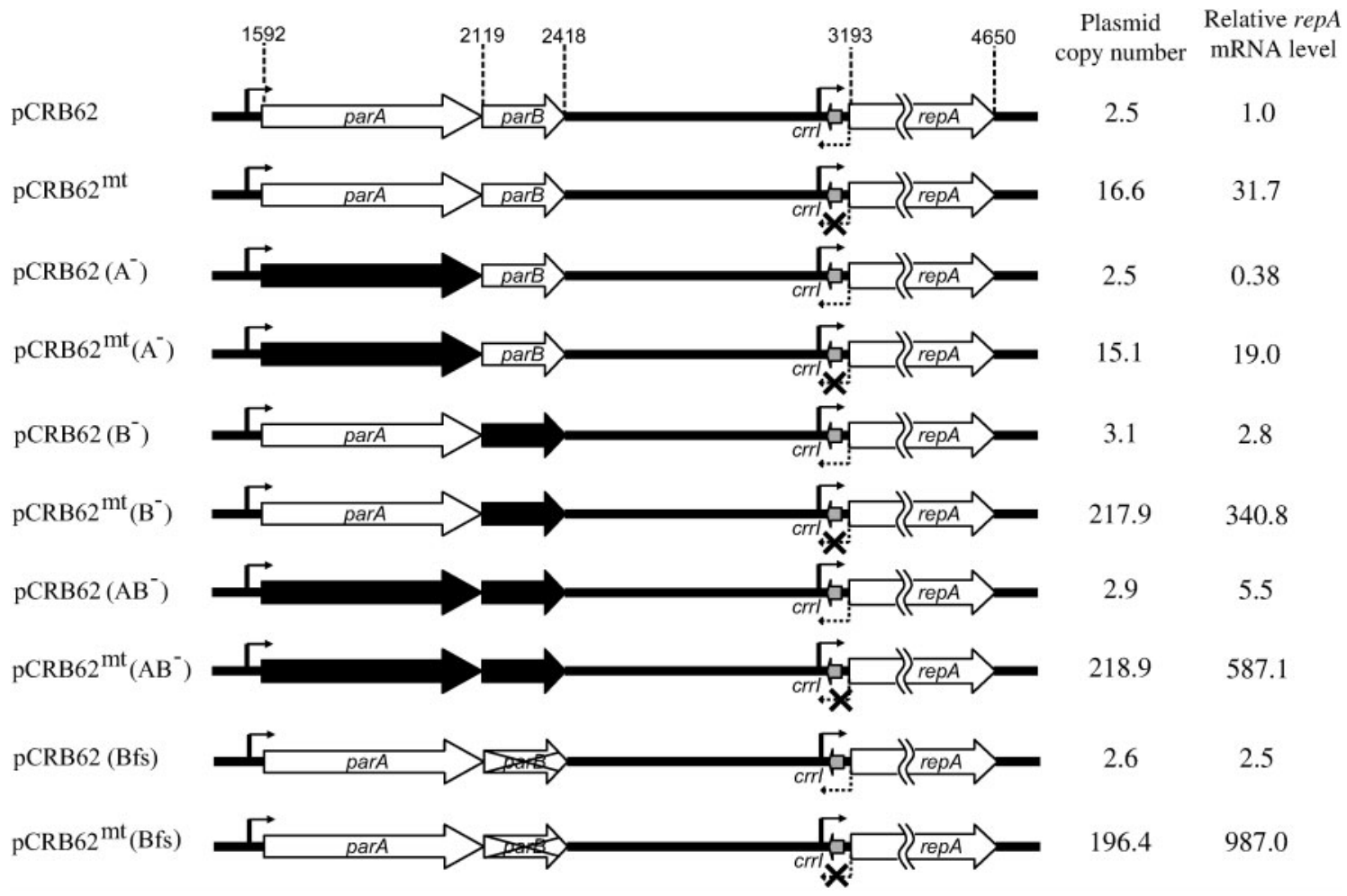

Fig. 4. Construction of pCGR2 plasmid derivatives and their copy numbers and relative repA mRNA levels. White arrows indicate ORFs (parA, parB and $\operatorname{rep} A$ ). Promoters of the parAB operon and repA are indicated by unbroken bent arrows. Small grey arrows indicate the antisense RNA gene, crrl, whose promoters are indicated by broken bent arrows. Where Pcrrl was inactivated by mutating the -10 region, the broken bent arrows are crossed. Black arrows indicate that the ORFs were deleted from the plasmid. Crossed arrows indicate that ParB protein was deactivated by frameshift mutation. The numbers 1592,2119 , 2418, 3193 and 4650 indicate the position on pCRB62.

the absence of CrrI resulted in a drastic increase in the plasmid copy number, which reached 218 copies per chromosome, a 73-fold increase compared with pCRB62 $\left(\mathrm{B}^{-}\right)$. Deleting both parA and parB ORFs had almost the same effect on plasmid copy number as deleting only parB. There was a $>100$-fold increase in the relative repA mRNA level when parB only, or both parA and parB, were deleted in the absence of CrrI. In order to examine if this phenomenon was caused by the functional absence of ParB, the protein was deactivated by frameshift mutagenesis. The deactivation resulted in the same effect on plasmid copy number as was observed by deleting the parB ORF. When the antisense RNA functioned normally, the removal of parB (or both parA and parB) or frameshifting par $B$ resulted in relatively marginal differences in plasmid copy number and relative mRNA level (Fig. 4).

\section{The terminal loop structure of antisense RNA plays an important role in copy number control}

In order to examine the effect of antisense RNA secondary structure on plasmid replication control, site-directed mutagenesis was performed by inverse PCR. Nucleotide substitutions were designed not to alter the SD sequence or insert extra initiation codons in the rep leader region. A total of six mutants, CrrI-mt1 to CrrI-mt6 (Table 3), were constructed using pCRB62 $\left(\mathrm{B}^{-}\right)$as template, expecting the effect of site-directed mutagenesis to be most clearly observed in the absence of parB. Each mutant contained single or double nucleotide substitutions which were predicted to cause no major secondary structure changes of either CrrI or its target mRNA (data not shown). Minimum free energy was the same or even lower in some cases (Table 3). C. glutamicum was successfully transformed with plasmids containing CrrI-mt1, 2, 3 and 6 . However, plasmids containing CrrI-mt4 (one internal loop disrupted) and CrrI-mt5 (both internal loops disrupted) failed to replicate. CrrI-mtl contained one nucleotide substitution, which disrupted the GNRA motif in LoopII, but the YUNR motif in sense RNA (LoopII') remained intact. CrrI-mt2, on the other hand, comprised the intact GNRA motif (silent mutation) but with the YUNR motif in LoopII' disrupted. In CrrI-mt3 double nucleotide substitution disrupted both motifs. Plasmid copy number increased 2.5-fold upon disruption of the GNRA motif of CrrI (CrrI-mt1), whereas a lesser increase (1.6-fold) was 
Table 3. Mutant forms of pCGR2 and pCG1 antisense RNAs and plasmid copy numbers

\begin{tabular}{|c|c|c|c|c|c|c|c|}
\hline $\begin{array}{l}\text { Antisense } \\
\text { RNA }\end{array}$ & $\begin{array}{l}\text { Position of } \\
\text { nucleotide } \\
\text { substitution }\end{array}$ & $\begin{array}{c}\text { Minimum free energy } \\
(\Delta G)\left(\mathrm{kcal} \mathrm{mol}^{-1}\right) \\
{\left[\mathrm{kJ} \mathrm{mol}{ }^{-1}\right]}\end{array}$ & $\begin{array}{c}\text { Presence of GNRA in antisense } \\
\text { RNA loop (LoopII) }\end{array}$ & $\begin{array}{l}\text { Presence of YUNR in sense } \\
\text { RNA loop }(\text { LoopII') }\end{array}$ & Other features & $\begin{array}{l}\text { Plasmid } \\
\text { copy no.* }\end{array}$ & $\begin{array}{c}\text { Plasmid copy } \\
\text { no. increase } \\
\text { (fold) }\end{array}$ \\
\hline CrrI (WT) & - & $-41.8[-174.9]$ & Yes (GCAA) & Yes (CUUG) & & 3.0 & 1.0 \\
\hline CrrI-mtl & G50U & $-41.8[-174.9]$ & No $(\mathrm{GCAA} \rightarrow \mathrm{UCAA})$ & Yes (CUUG) & & 7.6 & 2.5 \\
\hline CrrI-mt2 & $\mathrm{C} 51 \mathrm{G}$ & $-41.8[-174.9]$ & Yes $(\mathrm{GCAA} \rightarrow \mathrm{GGAA})$ & No $($ CUUG $\rightarrow$ CUUC) & & 4.9 & 1.6 \\
\hline CrrI-mt3 & G50U, C51G & $-41.8[-174.9]$ & No $($ GCAA $\rightarrow$ UGAA $)$ & No $(\mathrm{CUUG} \rightarrow \mathrm{CUUC})$ & & 8.1 & 2.7 \\
\hline CrrI-mt4 & U27G & $-48.9[-204.6]$ & Yes (GCAA) & Yes (CUUG) & One internal loop closed & $\mathrm{ND}$ & $\mathrm{ND}$ \\
\hline CrrI-mt5 & $\mathrm{U} 27 \mathrm{G}, \mathrm{U} 30 \mathrm{~A}$ & $-52.2[-218.4]$ & Yes (GCAA) & Yes (CUUG) & Both internal loops closed & ND & $\mathrm{ND}$ \\
\hline \multirow[t]{2}{*}{ CrrI-mt6 } & G47C & $-46.2[-193.3]$ & Yes (GCAA) & YUNR $\rightarrow$ UNR motif $(\mathrm{CUUG} \rightarrow$ UUC) & LoopII size $8 \mathrm{bp} \rightarrow 6 \mathrm{bp}$ & 2.8 & 0.94 \\
\hline & & & $\begin{array}{c}\text { Presence of YUNR in antisense } \\
\text { RNA loop (LoopI) }\end{array}$ & $\begin{array}{c}\text { Presence of GNRA in sense } \\
\text { RNA loop }(\text { LoopII') }\end{array}$ & & & \\
\hline CgrI (WT) & - & $-43.8[-183.3]$ & Yes (UUGG) & Yes (GUAA) & & 4.6 & 1.0 \\
\hline CgrI-mt1 & U19G & $-43.8[-183.3]$ & $\mathrm{YUNR} \rightarrow \mathrm{UNR}$ motif $(\mathrm{UUGG} \rightarrow \mathrm{GUGG})$ & Yes (GUAA) & & 5.0 & 1.1 \\
\hline CgrI-mt2 & G21C & $-43.8[-183.3]$ & Yes $($ UUGG $\longrightarrow$ UUCG $)$ & Yes (GUAA) & & 5.2 & 1.1 \\
\hline CgrI-mt3 & U19G, U20A & $-43.8[-183.3]$ & No (UUGG $\rightarrow$ GAGG) & Yes (GUAA) & & 6.6 & 1.4 \\
\hline CgrI-mt4 & U31A, U32A & $-48.3[-202.1]$ & Yes (UUGG) & Yes (GUAA) & Internal loop closed & ND & $\mathrm{ND}$ \\
\hline CgrI-mt5 & $\mathrm{A} 23 \mathrm{C}$ & $-47.5[-198.7]$ & Yes (UUGG) & Yes (GUAA) & LoopI size $7 \mathrm{bp} \longrightarrow 5 \mathrm{bp}$ & 11.3 & 2.4 \\
\hline
\end{tabular}

${ }^{\star}$ Copy number of each of four $d n a A$ and $a p h$ targets was quantified in quadruplicate to calculate the plasmid copy number.

ND, Not determined. 
observed upon disruption of the YUNR motif in target mRNA (CrrI-mt2). Removing both motifs resulted in a 2.7-fold copy number increase (CrrI-mt3), equivalent to the level observed when only the GNRA motif was disrupted. The effect of the single-strand loop size on the plasmid copy number was examined using CrrI-mt6. The size of LoopII was reduced from $8 \mathrm{bp}$ to $6 \mathrm{bp}$ with the GNRA motif still intact. However, shortening the loop by 2 bp did not affect plasmid copy number (0.94 relative to wild-type).

A total of five CgrI mutants were constructed (CgrI-mt1 to CgrI-mt5) by single or double nucleotide substitution (Table 3). In CgrI-mt1, 2 and 3, the nucleotide substitution was introduced within the YUNR motif in LoopI. The YUNR motif was altered to a UNR motif in CgrI-mt1, whereas a single base substitution in CgrI-mt2 was introduced in the ' $\mathrm{N}$ ' region of YUNR, the motif remaining intact (silent mutation). Double nucleotide substitution in CgrI-mt3 completely disrupted the YUNR motif. In CgrI$\mathrm{mt} 4$ the internal loop was closed by substitution of two nucleotides. In CgrI-mt5 the YUNR motif remained intact but the size of the terminal single-strand loop was reduced from $7 \mathrm{bp}$ to $5 \mathrm{bp}$. Based on the RNAfold program, the basic secondary structures of the CgrI mutants and their target mRNA regions were maintained (data not shown), with the same or even lower minimum free energy (Table 3). A single exception was a major structural change in stem length of the target mRNA of CgrI-mt4: StemII' was shortened by $4 \mathrm{bp}$ and StemI' became $7 \mathrm{bp}$ longer, although the single-strand loops remained intact (data not shown). Again, CgrI-mt4, whose internal loop was disrupted, seemed not to be able to replicate in $C$. glutamicum, as no transformant could be obtained. Neither changing the YUNR motif to UNR nor inserting a silent mutation in YUNR resulted in any clear difference in plasmid copy number. Disrupting the YUNR motif in LoopII' of CgrI caused a moderate increase in copy number (4.6 to 6.6). In contrast to CrrI, reducing the LoopI size by 2 bp clearly hindered the inhibitory effect of CgrI, resulting in a copy number increase of about 2.4 -fold (Table 3).

\section{Antisense-RNA-mediated plasmid replication control is probably a common feature of most corynebacterial pCG1 family plasmids}

Having established the presence and function of antisense RNA of pCGR2 and pCG1 we raised the hypothesis that this is a common mechanism of pCG1 family plasmids. Homology search revealed similar sequences not only in other C. glutamicum pCG1 family plasmids such as pTET3, pAG1 and pCG4, but also in other related plasmids from Corynebacterium species, including pCJ84, pA501, pK43, pK64, pKW4, pA505, pB85766, pTP10, pNG2, pYM2, pBY503 and pCE2 (Fig. 5). However, pGA2 from $C$. glutamicum, pCE3 from Corynebacterium efficiens and pLEW279a from Corynebacterium sp. L2-79-05 did not reveal any sequences similar to those encoding antisense RNA. It is not clear whether these plasmids code for phylogenetically unrelated antisense RNA genes, or they simply do not employ antisense RNA for plasmid replication control. This observation suggests that the antisense-RNA-mediated plasmid replication control system is shared among most of the corynebacterial pCG1 family plasmids, with only a few exceptions. An unrooted dendrogram of RepA amino acid sequences from Corynebacterium pCG1 family plasmids with pBL1 plasmid as outgroup is shown in Fig. 6. The dendrogram comprises five distinct clusters: cluster $\mathrm{S}$ comprises plasmids $3-4.8 \mathrm{~kb}$ in size, including small pCG1-subfamily members, which do not contain partitioning genes. Clusters P1 through P4 comprise plasmids harbouring partitioning genes (the presence of partitioning genes is not known in pBY503, pTP10 and pCE3). Larger pCG1-subfamily members of $C$. glutamicum are scattered in clusters P1, P2 and P4. Cluster P3 consists solely of plasmids from Corynebacterium species other than C. glutamicum.

Plasmids classified in the same cluster based on RepA amino acid sequence similarity also showed higher sequence similarity in repA leader regions (Fig. 5). Antisense RNAs of all the plasmids shown in Fig. 5, except for pBY503 and pCE2, were predicted to form a secondary structure with two stem-loops. The antisense RNAs of pBY503 and pCE2 were partially homologous to other cluster P1 and P2 members, respectively, but they were longer and they were predicted to form three stem-loops. The putative -10 and -35 regions of antisense RNA genes were conserved, except that the -35 region of cluster P3 plasmids was not obvious. Even closely related antisense RNAs within the same cluster showed versatility in singlestrand-loop regions (Fig. 5). In general, each antisense RNA loop contained the U-turn motif(s) and/or a full or partial sequence complementary to the U-turn motif on sense RNA; the exception was the LoopI region of cluster P1 plasmids (pCGR2, pTET3 and pNG2).

\section{DISCUSSION}

The recent isolation of a large $(24 \mathrm{~kb})$ C. glutamicum plasmid, pCGR2 (Tsuchida et al., 2010), added an eighth member to the C. glutamicum pCG1 family plasmids pCG1, pGA1, pSR1, pTET3, pGA1, pCG4 and pGA2 (Tauch, 2005). A preliminary experiment indicated the possible involvement of antisense RNA in pCGR2 copy number control (Tsuchida et al., 2010). In this study we established the existence of an antisense RNA replication control system in pCGR2 and pCG1, plasmids that belong to distinct C. glutamicum pCG1 subfamilies.

Plasmids pCGR2 and pCG1 expressed short antisense RNAs, CrrI and CrgI, respectively, which were somewhat shorter than that identified in pGA1 (89 bp, VenkovaCanova et al., 2003). Both CgrI and CrrI were predicted to form stable secondary structures, each comprising two 
repA (complement)

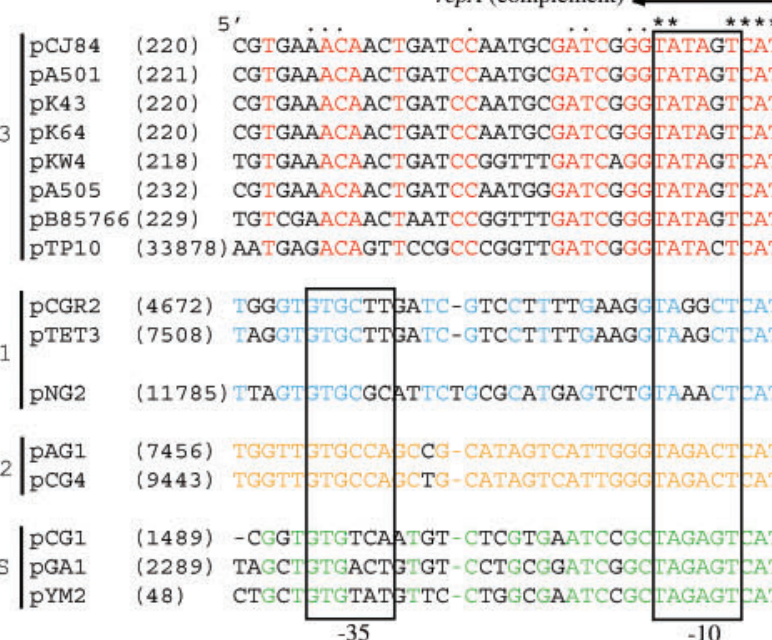

$\star * * * * *, * * *, * *$

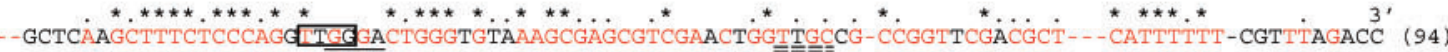

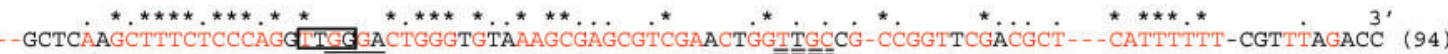
-GACCAAGCTTTCTCCCAGGTAGTGGCTGGGTGTAAAGCGAGCGTCGAACTGGTTGCAG-CCGGTTCGGCGCT---CATTTTTTITCGTTTCGACC (94) GCTCAAGCTTTCTCCCAG GITGG GACTGGGTGTAAAGCGAGCGTCGAACTGGTTCCCG-CCGGTTCGGCGCT - - - CATTTTTTTCGTTTCGACC (93) -GCTCAAGCTTTCTCCCAG dTTGGGA CTGGGTGTAAAGCGAGCGTCGAACTGGTTGCCG-CCGGTTCGGCGCT- - - CATTTTTTTTCGTTTCGACC (93) -ACTCAAGCTTTCTCCCAGGT-GGGA CTGGGGGTAAAGCGAGCGTCGAACTGGTAGCCG-CCGGTTCGGCGCT- - -CATTTTTTT-CGTTTCGACC (93) -GCTCAAGCTTTCTCCCACAUGG SACTGGGTGTAAAGCGAGCGTCGAACTGGTTGCAG-CCGGTTCGGCGCT - - -CATTTTTTTCGTTTCGACC (94) -

- - -GTCTAGGCTTTCTCCCAGATTGTGGCTGGGTGATAAGCGAGCGTCGATCCGGTTGCCG-CCGGT-CGGCGCT---CATTTTTT--TATTCGGTT $(34000)$ -TGA 5'

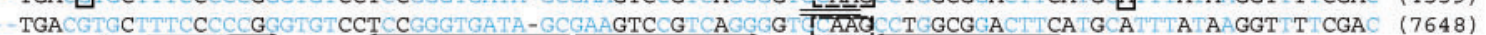

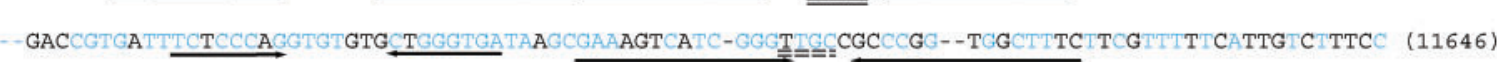
AAACCAAGCTTTCCCCCAGGTT ETGA CTGGGCATAAGCGAACACCTTACGAGA -AACCAAGCTTTCCCCCAGGTTCTCA CTGGG TGATAAGCGAACACCTTACGAGCACCCTCGTAGGGTGTT--CTITTTTGTGTAGTTGTTT (9304)

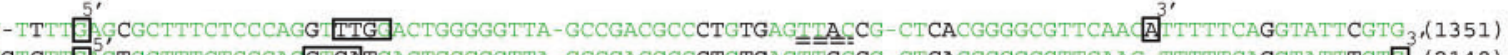

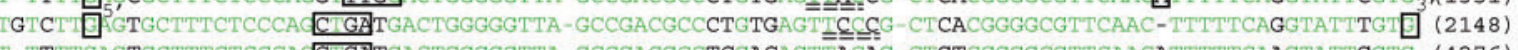

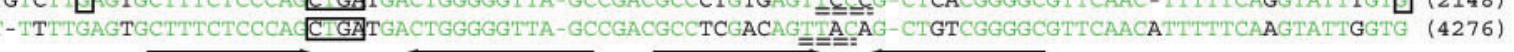
LoopI $\longrightarrow$ LoopI

repA (complement)

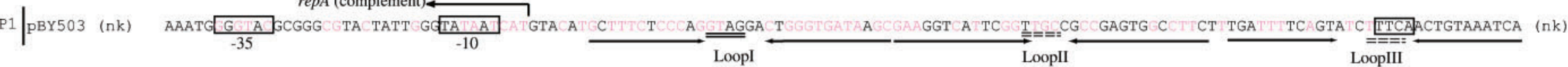

repA (complement)

P2 pCE2 (8465) TGGTI $\frac{\text { GTGCCA }}{-35}$;ACGTCGTGCTATTGAC GCTGGTGGGTTTCGCTITCATTGTTAAGTTCTITTC (8281) GAC] CATAGCCATGCTTTCCCCGGTA

Fig. 5. Comparison of the mRNA leader region of Corynebacterium pCG1 family plasmids. The -10 and -35 regions of the antisense RNA genes are boxed and marked ' -10 ' and ' -35 ', respectively. Asterisks mark identical nucleotides and dots indicate nucleotides that are semi-conserved (two different nucleotides appeared). Red, blue, orange and green letters indicate identical nucleotides among plasmids belonging to Cluster P3, P1 (excluding pLEW279a and pBY503), P2 (excluding pCE2) and S, respectively. Nucleotides of pBY503 showing homology to three other Cluster P1 members (pCGR2, pTET3 and pNG2) are coloured in pink. Nucleotides of pCE2 showing homology to two other Cluster P2 members (pAG1 and pCG4) are coloured in purple. Arrows show the position and orientation of the antisense RNA stem regions. Loopl, Loopll and Looplll indicate the positions of terminal loops. The YUNR motif on antisense RNA is boxed. The GNRA/GNRG motif on antisense RNA is double-underlined. The complementary sequence of the YUNR motif formed on the target mRNA is boxed with broken lines. The complementary sequence of the GNRA/GNRG motif formed on the target mRNA is underlined with double broken lines. The $5^{\prime}$ - and $3^{\prime}$-ends of Crrl and Cgrl determined in this study, and those of pGA1 (Venkova-Canova et al., 2003), are boxed and labelled either ' 5 " or ' 3 ", respectively. The numbers in parentheses indicate the position on the plasmid sequence. nk, not known. 


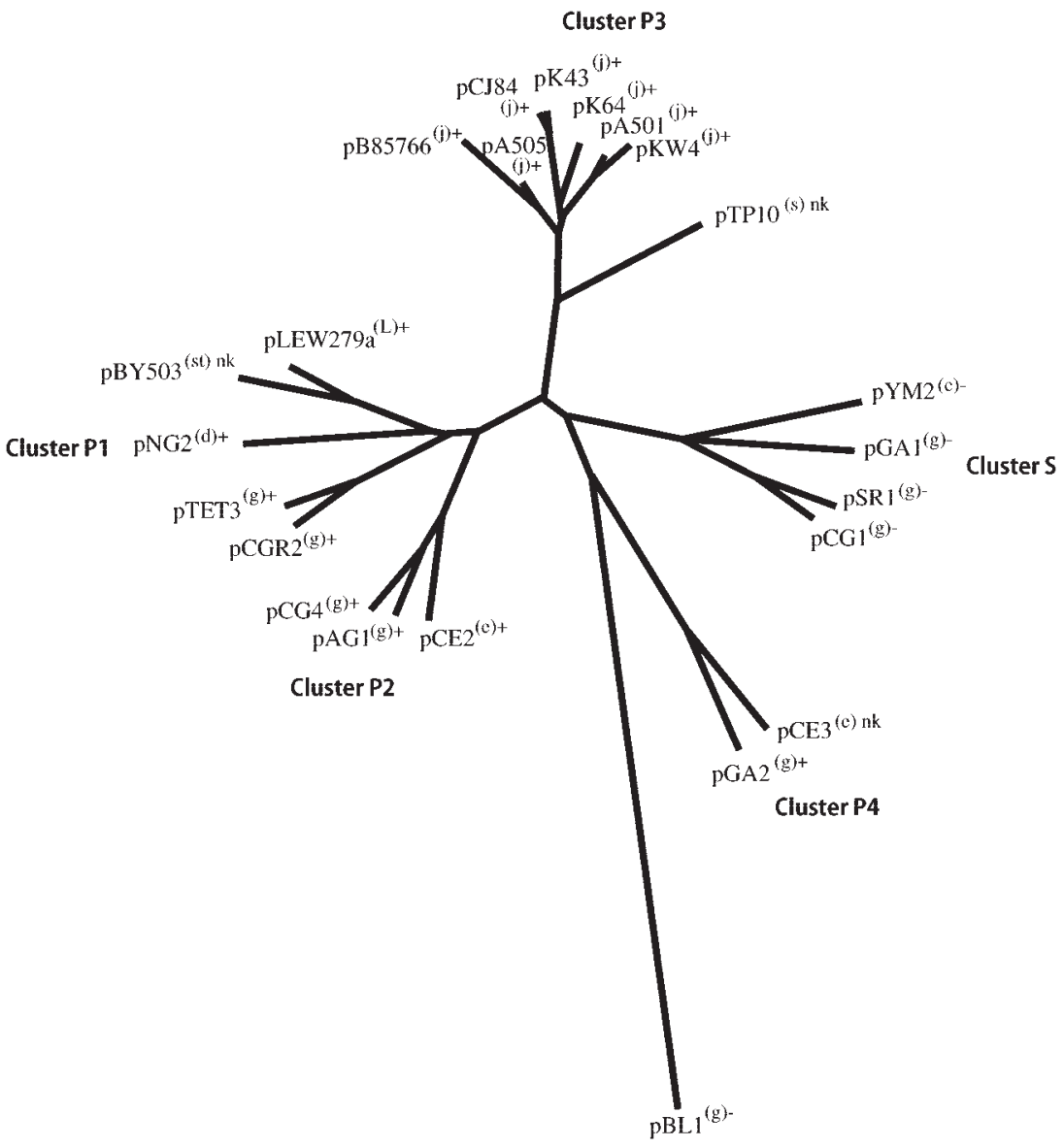

Fig. 6. Unrooted dendrogram of RepA amino acid sequences from Corynebacterium pCG family plasmids (pBL1 plasmid as comparison). The unrooted dendrogram comprises five distinct clusters (S and P1-P4). Plasmid names marked with (d), (e), (g), (j), (s), (L) and (st) indicate origin from Corynebacterium diphtheriae, Corynebacterium efficiens, Corynebacterium glutamicum, Corynebacterium jeikeium, Corynebacterium striatum, Corynebacterium sp. L279-05 and Corynebacterium stationis (formerly called Brevibacterium stationis; Bernard et al., 2010), respectively. +/- indicates the presence/absence of putative partitioning genes, respectively. nk, not known. GenBank accession numbers are as follows: pCG1, BAA78091; pSR1, CAA80508; pAG1, AAD25058; pCE2, BAC19765; pCE3, BAC19786; pCG4, AAG00275; pGA1, CAA62330; pGA2, AAO18208; pTET3, CAD12209; pYM2, BAB91405; pTP10, NP_862246; pA505, NP_848176; pB85766, NP_612158; pNG2, AAM̄12773; pCJ84, AAL̄06089; pK43, AAK52805; pK64, AAL85937; pA501, AAP22001; pKW4, AAK94044; pLEW279a, YP_001096213; pBY503, E08498; pCGR2, YP_003377690; pBL1; YP_001649178.

stem-loops. The presence of a sequence complementary to the repA SD sequence in both CrrI and CgrI implied that the antisense RNAs act negatively at the post-transcriptional level. Given the fact that a far greater effect of CrrI and CgrI on repA mRNA level than on plasmid copy number was observed, it is also possible that CrrI and CgrI are involved in transcription attenuation. The mutation introduced into the pGA1 antisense RNA promoter region by Venkova-Canova et al. (2003) brought about a two amino acid replacement in its RepA protein, which we thought might have caused some interference in interpreting the data. However, the increase in copy number observed for pCRB62 and pCRB12 (about sevenfold) was similar to that reported for pGA1 (eightfold).

Introducing mutations into CrrI and CgrI to disrupt internal loop(s) seemed to inhibit plasmid replication in $C$. glutamicum (and thus bacterial growth in the presence of antibiotics). Given the fact that inactivating the promoter of $c r r I$ and $c g r I$ did not affect bacterial growth, it is unlikely that this was caused by the functional absence of antisense RNA. Disruption of CrrI internal $\operatorname{loop}(\mathrm{s})$ was also predicted to eliminate the $\operatorname{loop}(\mathrm{s})$ of the target mRNA on which the repA SD sequence is located. As for CgrI, the repA SD sequence was not located on the internal loop (Fig. 3b), but disrupting the CgrI internal loop was predicted to cause a major structural change in the target
mRNA. One could therefore presume that this structural change in mRNA may, at least partially, have caused an inhibitory effect on RepA translation. Kim et al. (2008) reported difficulty in constructing antisense RNA mutants. As the authors suggested, this may also have been caused by some pleiotropic effects.

Binding of antisense RNA and its target mRNA often occurs through loop-loop contacts called 'kissing complexes', contacts which progress into the lower stem regions (Heidrich \& Brantl, 2007). Determinants for efficient inhibition by antisense RNA include the presence of U-turn motifs as well as the size of antisense or sense RNA terminal loops (Heidrich \& Brantl, 2007; Hjalt \& Wagner, 1992). The antisense GNRA motif seems to play a major role as a determinant for efficient inhibition by CrrI. Disrupting the antisense YUNR motif of CgrI resulted in a lower increase in the plasmid copy number compared with CrrI. The plasmid copy number was affected differently by modifying the terminal loop size of CrrI and CgrI. Although the observed copy number increase was generally moderate in this study (maximum 2.7-fold increase), it was significant in that alteration of YUNR to UNR and an introduction of a silent mutation resulted in the same copy number as the wild-type. The results indicate that terminal loop structure characteristics, such as the U-turn motif and loop size, are important for the efficient antisense 
RNA-mRNA interaction, and thus copy number control. The extent of inhibitory effect caused by each of these factors can, however, vary with each plasmid.

In the complete absence of antisense RNAs, copy numbers of the parental plasmids, pCRB62 $\left(\mathrm{B}^{-}\right)$and pCRB12, could reach a maximum of 218 and 30.8 copies per chromosome, respectively, even though the copy number increase observed for each tested mutant was only moderate. Combinations of a variety of factors related to RNA structure are therefore probably responsible for the complete functionality of antisense RNAs.

The antisense-RNA-mediated plasmid replication control system is likely to be the prevailing feature not only in other C. glutamicum pCG1 family members, but also in other related plasmids from Corynebacterium species. Based on the phylogeny of RepA and antisense RNA it was shown that the more similar the RepA sequences, the closer the antisense RNA sequences. A lack of sequence similarity was seen only in certain regions of pCE2 antisense RNA compared with other cluster P2 members, implying that insertion of the region took place during evolution. pSR1 probably originates from pCG1 (98\% sequence identity) but has partially lost the original pCG1 RepA amino acid sequence. Whether or not the cgrI homologue found in pSR1 actually functions in repA regulation is unclear. pGA2 and pCE3 were branched out in the dendrogram (cluster P4; Fig. 6), which was consistent with the absence of similar antisense-RNA-like sequences. Other than the two plasmids in cluster P4, pLEW279a was the only exception that did not contain a similar antisense-RNA-like sequence. Characteristics of the predicted single-stranded terminal loops, such as the presence of U-turn motif(s), a difference in a few nucleotides and loop size, etc., were found to be unique to each plasmid in most cases. Such differences may determine the plasmid replication control ability, which is unique to individual plasmids.

Absence of the putative gene (parB) encoding the centromere-binding protein caused an unexpectedly dramatic increase in repA mRNA levels as well as plasmid copy numbers, but only when synthesis of CrrI was abolished. The observation is unlikely to be related to the readthrough transcription of the parAB operon into the repA gene, since Tsuchida et al. (2010) reported an increase in the copy number of a pCGR2-derived plasmid, pCRD329, from which the parAB promoter as well as ORFs were deleted. Since this was not caused by structural changes in the plasmid by deleting the par gene(s), but by functional absence of ParB protein, the following could be considered as reasons for this observation. (i) ParB proteins bind to the centromere site on plasmid DNA to form the partitioning complex, which physically limits the space for plasmid replication. The effect of the absence of ParB may become much more obvious when antisense RNA defeats its function, allowing an uncontrolled number of plasmids to co-exist within the cell. (ii) ParB serves directly or indirectly as rep regulator: e.g. de la $\mathrm{Hoz}$ et al. (2000) reported the centromere-binding $\omega$ protein, which functions as a global regulator for plasmid number control in pSM19035. A study to elucidate the molecular mechan$\operatorname{ism}(s)$ involved in this process is under way in our laboratory.

Regardless of the mechanism involved in the drastic increase in plasmid copy number upon deactivation of ParB, CrrI exerts significant negative control over plasmid replication: CrrI was able to maintain plasmid copy number at wild-type levels even in the absence of ParB. Considering that plasmid maintenance imposes a metabolic burden on the host (Ow et al., 2006), such efficient control of copy number must have been crucial to sustainable evolution of plasmid DNA. The presence of putative partitioning genes seems widespread among members of pCG1 family plasmids other than the small members in cluster $S$, and it would be interesting to know whether such copy number increase following deletion of parB occurs in other plasmids as well. Manipulation of antisense RNA as well as partitioning genes may serve as a novel approach to artificially elevate the plasmid copy number for this purpose.

This study looked at phylogenetically related plasmids from the viewpoint of antisense-RNA-mediated plasmid replication control systems. Revealing the plasmid replication mechanism should not only be of scientific interest but also provide us with basic knowledge relevant to establishing better genetic engineering tools for C. glutamicum.

\section{ACKNOWLEDGEMENTS}

We would like to thank Dr Crispinus A. Omumasaba for critical reading of the manuscript. We gratefully acknowledge Dr Wataru Gunji and Ryoji Noburyu for constructing vectors pCRB62 and pCRB12, respectively. This work was supported by a grant from the New Energy and Industrial Technology Development Organization (NEDO), Japan.

\section{REFERENCES}

Archer, J. A. \& Sinskey, A. J. (1993). The DNA sequence and minimal replicon of the Corynebacterium glutamicum plasmid pSR1: evidence of a common ancestry with plasmids from C. diphtheriae. J Gen Microbiol 139, 1753-1759.

Athanasopoulos, V., Praszkier, J. \& Pittard, A. J. (1999). Analysis of elements involved in pseudoknot-dependent expression and regulation of the repA gene of an IncL/M plasmid. J Bacteriol 181, 18111819.

Bernard, K. A., Wiebe, D., Burdz, T., Reimer, A., Ng, B., Singh, C., Schindle, S. \& Pacheco, A. L. (2010). Assignment of Brevibacterium stationis (ZoBell and Upham 1944) Breed 1953 to the genus Corynebacterium, as Corynebacterium stationis comb. nov., and emended description of the genus Corynebacterium to include isolates that can alkalinize citrate. Int J Syst Evol Microbiol 60, 874-879.

Brantl, S. (2002). Antisense RNAs in plasmids: control of replication and maintenance. Plasmid 48, 165-173. 
Brantl, S. (2007). Regulatory mechanisms employed by cis-encoded antisense RNAs. Curr Opin Microbiol 10, 102-109.

Brune, I., Becker, A., Paarmann, D., Albersmeier, A., Kalinowski, J., Puhler, A. \& Tauch, A. (2006). Under the influence of the active deodorant ingredient 4-hydroxy-3-methoxybenzyl alcohol, the skin bacterium Corynebacterium jeikeium moderately responds with differential gene expression. J Biotechnol 127, 21-33.

Davison, J. (1984). Mechanism of control of DNA replication and incompatibility in ColE1-type plasmids - a review. Gene 28, 1-15.

de la Hoz, A. B., Ayora, S., Sitkiewicz, I., Fernandez, S., Pankiewicz, R., Alonso, J. C. \& Ceglowski, P. (2000). Plasmid copy-number control and better-than-random segregation genes of pSM19035 share a common regulator. Proc Natl Acad Sci U S A 97, 728-733.

del Solar, G. \& Espinosa, M. (2000). Plasmid copy number control: an ever-growing story. Mol Microbiol 37, 492-500.

del Solar, G., Giraldo, R., Ruiz-Echevarria, M. J., Espinosa, M. \& Diaz-Orejas, R. (1998). Replication and control of circular bacterial plasmids. Microbiol Mol Biol Rev 62, 434-464.

Franch, T. \& Gerdes, K. (2000). U-turns and regulatory RNAs. Curr Opin Microbiol 3, 159-164.

Franch, T., Petersen, M., Wagner, E. G., Jacobsen, J. P. \& Gerdes, K. (1999). Antisense RNA regulation in prokaryotes: rapid RNA/RNA interaction facilitated by a general U-turn loop structure. J Mol Biol 294, 1115-1125.

Gutell, R. R., Cannone, J. J., Konings, D. \& Gautheret, D. (2000). Predicting U-turns in ribosomal RNA with comparative sequence analysis. J Mol Biol 300, 791-803.

Heidrich, N. \& Brantl, S. (2007). Antisense RNA-mediated transcriptional attenuation in plasmid pIP501: the simultaneous interaction between two complementary loop pairs is required for efficient inhibition by the antisense RNA. Microbiology 153, 420-427.

Hjalt, T. \& Wagner, E. G. (1992). The effect of loop size in antisense and target RNAs on the efficiency of antisense RNA control. Nucleic Acids Res 20, 6723-6732.

Hofacker, I. L., Fontana, W., Stadler, P. F., Bonhoeffer, L. S., Tacker, M. \& Schuster, P. (1994). Fast folding and comparison of RNA secondary structures. Monatsh Chem 125, 167-188.

Inui, M., Suda, M., Okino, S., Nonaka, H., Puskas, L. G., Vertes, A. A. \& Yukawa, H. (2007). Transcriptional profiling of Corynebacterium glutamicum metabolism during organic acid production under oxygen deprivation conditions. Microbiology 153, 2491-2504.

Katsumata, R., Ozaki, A., Oka, T. \& Furuya, A. (1984). Protoplast transformation of glutamate-producing bacteria with plasmid DNA. J Bacteriol 159, 306-311.

Khan, S. A. (1997). Rolling-circle replication of bacterial plasmids. Microbiol Mol Biol Rev 61, 442-455.

Kim, S. W., Jeong, I. S., Jeong, E. J., Tak, J. I., Lee, J. H., Eo, S. K., Kang, H. Y. \& Bahk, J. D. (2008). The terminal and internal hairpin loops of the ctRNA of plasmid pJB01 play critical roles in regulating copy number. Mol Cells 26, 26-33.

Kinoshita, S., Udaka, S. \& Shimono, M. (1957). Studies on the amino acid fermentation. Part I. Production of L-glutamic acid by various microorganisms. J Gen Appl Microbiol 3, 193-205.

Kurusu, Y., Satoh, Y., Inui, M., Kohama, K., Kobayashi, M., Terasawa, M. \& Yukawa, H. (1991). Identification of plasmid partition function in coryneform bacteria. Appl Environ Microbiol 57, 759-764.

Le Chatelier, E., Ehrlich, S. D. \& Janniere, L. (1996). Countertranscriptdriven attenuation system of the pAM $\beta 1$ repE gene. Mol Microbiol 20, 1099-1112.

Nešvera, J., Pátek, M., Hochmannova, J., Abrhamova, Z., Becvarova, V., Jelinkova, M. \& Vohradsky, J. (1997). Plasmid pGA1 from
Corynebacterium glutamicum codes for a gene product that positively influences plasmid copy number. J Bacteriol 179, 1525-1532.

Nishio, Y., Nakamura, Y., Kawarabayasi, Y., Usuda, Y., Kimura, E., Sugimoto, S., Matsui, K., Yamagishi, A., Kikuchi, H. \& other authors (2003). Comparative complete genome sequence analysis of the amino acid replacements responsible for the thermostability of Corynebacterium efficiens. Genome Res 13, 1572-1579.

Novick, R. P., Iordanescu, S., Projan, S. J., Kornblum, J. \& Edelman, I. (1989). pT181 plasmid replication is regulated by a countertranscriptdriven transcriptional attenuator. Cell 59, 395-404.

Ow, D. S.-W., Nissom, P. M., Philp, R., Oh, S. K.-W. \& Yap, M. G.-S. (2006). Global transcriptional analysis of metabolic burden due to plasmid maintenance in Escherichia coli DH5 during batch fermentation. Enzyme Microb Technol 39, 391-398.

Ozaki, A., Katsumata, R., Oka, T. \& Furuya, A. (1984). Functional expression of the genes of Escherichia coli in Gram-positive Corynebacterium glutamicum. Mol Gen Genet 196, 175-178.

Pátek, M., Nešvera, J., Guyonvarch, A., Reyes, O. \& Leblon, G. (2003). Promoters of Corynebacterium glutamicum. J Biotechnol 104, 311-323.

Rasooly, A. \& Rasooly, R. S. (1997). How rolling circle plasmids control their copy number. Trends Microbiol 5, 440-446.

Sambrook, J., Fritsch, E. F. \& Maniatis, T. (1989). Molecular Cloning: a Laboratory Manual, 2nd edn. Cold Spring Harbor, NY: Cold Spring Harbor Laboratory.

Siemering, K. R., Praszkier, J. \& Pittard, A. J. (1994). Mechanism of binding of the antisense and target RNAs involved in the regulation of IncB plasmid replication. J Bacteriol 176, 2677-2688.

Sonnen, H., Thierbach, G., Kautz, S., Kalinowski, J., Schneider, J., Pühler, A. \& Kutzner, H. J. (1991). Characterization of pGA1, a new plasmid from Corynebacterium glutamicum LP-6. Gene 107, 69-74.

Takeda, Y., Fujii, M., Nakajyoh, Y., Nishimura, T. \& Isshiki, S. (1990). Isolation of a tetracycline resistance plasmid from a glutamateproducing Corynebacterium, Corynebacterium melassecola. J Ferment Bioeng 70, 177-179.

Tauch, A. (2005). Native plasmids of amino acid-producing corynebacteria. In Handbook of Corynebacterium Glutamicum, pp. 57-80. Edited by L. Eggeling \& M. Bott. Boca Raton, FL: CRC Press.

Tauch, A., Krieft, S., Kalinowski, J. \& Puhler, A. (2000). The 51,409-bp R-plasmid pTP10 from the multiresistant clinical isolate Corynebacterium striatum M82B is composed of DNA segments initially identified in soil bacteria and in plant, animal, and human pathogens. Mol Gen Genet 263, 1-11.

Tauch, A., Gotker, S., Pühler, A., Kalinowski, J. \& Thierbach, G. (2002). The 27.8-kb R-plasmid pTET3 from Corynebacterium glutamicum encodes the aminoglycoside adenyltransferase gene cassette aadA9 and the regulated tetracycline efflux system Tet 33 flanked by active copies of the widespread insertion sequence IS6100. Plasmid 48, 117-129.

Tauch, A., Bischoff, N., Brune, I. \& Kalinowski, J. (2003a). Insights into the genetic organization of the Corynebacterium diphtheriae erythromycin resistance plasmid pNG2 deduced from its complete nucleotide sequence. Plasmid 49, 63-74.

Tauch, A., Pühler, A., Kalinowski, J. \& Thierbach, G. (2003b). Plasmids in Corynebacterium glutamicum and their molecular classification by comparative genomics. J Biotechnol 104, 27-40.

Tauch, A., Bischoff, N., Puhler, A. \& Kalinowski, J. (2004). Comparative genomics identified two conserved DNA modules in a corynebacterial plasmid family present in clinical isolates of the opportunistic human pathogen Corynebacterium jeikeium. Plasmid 52, 102-118. 
Tauch, A., Kaiser, O., Hain, T., Goesmann, A., Weisshaar, B., Albersmeier, A., Bekel, T., Bischoff, N., Brune, I. \& other authors (2005). Complete genome sequence and analysis of the multiresistant nosocomial pathogen Corynebacterium jeikeium K411, a lipid-requiring bacterium of the human skin flora. J Bacteriol 187, 4671-4682.

Tsuchida, Y., Kimura, S., Suzuki, N., Inui, M. \& Yukawa, H. (2009). Characterization of a new 2.4-kb plasmid of Corynebacterium casei and development of stable corynebacterial cloning vector. Appl Microbiol Biotechnol 81, 1107-1115.

Tsuchida, Y., Kimura, S., Suzuki, N., Inui, M. \& Yukawa, H. (2010). Characterization of a $24-\mathrm{kb}$ plasmid pCGR2 newly isolated from Corynebacterium glutamicum. Appl Microbiol Biotechnol 87, 18551866.

Venkova, T., Pátek, M. \& Nešvera, J. (2001). Identification of a novel gene involved in stable maintenance of plasmid pGA1 from Corynebacterium glutamicum. Plasmid 46, 153-162.
Venkova-Canova, T., Pátek, M. \& Nešvera, J. (2003). Control of rep gene expression in plasmid pGA1 from Corynebacterium glutamicum. J Bacteriol 185, 2402-2409.

Vertès, A. A., Inui, M., Kobayashi, M., Kurusu, Y. \& Yukawa, H. (1993). Presence of $\mathrm{mrr}$ - and $\mathrm{mcr}$-like restriction systems in coryneform bacteria. Res Microbiol 144, 181-185.

Williams, L. E., Detter, C., Barry, K., Lapidus, A. \& Summers, A. O. (2006). Facile recovery of individual high-molecular-weight, lowcopy-number natural plasmids for genomic sequencing. Appl Environ Microbiol 72, 4899-4906.

Yukawa, H., Omumasaba, C. A., Nonaka, H., Kós, P., Okai, N., Suzuki, N., Suda, M., Tsuge, Y., Watanabe, J. \& other authors (2007). Comparative analysis of the Corynebacterium glutamicum group and complete genome sequence of strain R. Microbiology 153, 1042-1058.

Edited by: C. W. Chen 